\title{
THE NATIONAL INSTITUTE FOR MEDICAL RESEARCH
}

\section{$\mathrm{T}$}

HE National Institute for Medical Research has lately moved to its new home on the Ridgeway, Mill Hill. On May 5 it was formally opened by His Majesty the King, accompanied by Her Majesty the Queen. For almost exactly thirty years its home has been at Mount Vernon, Holly Hill, Hampstead. One cannot say that Holly Hill knows it no more, for the building there will still house the Institute's Human Physiology Division, along with others of the Medical Research Council's research units.

The new Institute is a most impressive building of white Broomhill brick. Its seven stories, topped by a green copper roof, stand up on the Ridgeway and are visible from the Barnet by-pass road, and many other viewpoints around; from the ridge opposite, at Totteridge, it appears enormous. Of the many establishments of the Medical Research Council, this is by far the largest and it is, of course, something which is wholly the Council's. For many years the Hampstead Institute had been slowly growing, in the sense that more and more workers were being accommodated and pressure on space was becoming heavier. The Council's decision, in 1936, to accept responsibility for a big new programme of work at the Institute, on chemotherapy, made a move inevitable. The new building, designed by $\mathrm{Mr}$. Maxwell Ayrton, was begun in 1937, and the outer shell was complete in 1940. To finish and equip it at that time was clearly impossible. It was lent to the Admiralty for the preliminary training of Wrens (W.R.N.S.) between 1942 and 1946, and became for that period H.M.S. Elizabeth. Now, at last, its equipping is almost complete and it has returned to its intended purpose. It now houses a total staff of 335 ; ultimately the accommodation will suffice for 100 qualified workers and between 250 and 300 assistants and others.

The building's ground plan is an unusual one : the centre block is seven stories high; from each end of this sprout out two wings, set at an angle, but these only rise up for three stories. This form of the building was determined by the need for making the best possible use of the restricted amount of relatively level ground near the road; but it has the advantage of providing good lighting throughout. The two wings at the east end of the main building contain laboratories, as does the centre block; the wings at the west end (apart from the ground floor) house the quarters for experimental animals. Behind the centre block, away from the road, is the Fletcher Memorial Hall, for scientific meetings and other occasions. This is at ground-level in front, but has the extensive store rooms beneath it; it can seat 230. The name of the hall commemorates, of course, Sir Walter Fletcher, the Council's first secretary. In all there are 90,000 sq. $\mathrm{ft}$. of working space. The building is heated by hot-water panels; most of the illumination is by fluorescent lighting. Services laid on to various laboratories include pressure water, steam, compressed air, A.C., D.c. of various voltages, while distilled water is available from a central piped supply to points in corridors. Laboratories have been designed in close collaboration with heads of departments. It is inevitable that in the fourteen years since the building was first planned there have been many changes of staff and many develop- ments necessitating numerous drastic revisions in the original plans.

In the less specialized laboratories the benches are of teak, $2 \mathrm{ft}$. 6 in. or $3 \mathrm{ft}$. high as necessary ; the doors, too, are teak. The floors in general are of cork squares. Standard steel laboratory furniturecupboards, nests of drawers, and so on-are fitted and exchangeable with others held in reserve. In many rooms glass-fronted cupboards extend from a height of $6 \mathrm{ft}$. 6 in. to the ceiling, and these are conveniently reached by means of light aluminium ladders available in each room. The services are carried behind panels at the backs of the benches.

A tour of the Institute beginning at the bottom brings us first to the Division of Physiology and Pharmacology, where Dr. W. Feldberg and his colleagues carry on the traditions of Sir Henry Dale's laboratory. They are housed in the basement and sub-basement of the north-east wing; since the site of the Institute slopes sharply downwards away from the road, the laboratories are not so much underground as this description suggests. This position was chosen to enable them to have laboratories with a minimum of electrical interference. The problems of transmission of the nervous impulse still concern them, in particular the widely differing substances acting as histamine liberators, and the bisquaternary salts with curare-like action. Studies are also in progress on the activity of an isolated slab of cerebral cortex connected with the rest of the brain by its vascular supply only.

The centre block of the ground floor houses the office of the director, Sir Charles Harington, a conference room for small meetings, and administrative rooms. The south-west wing - and part of the northwest-accommodate the Division of Biophysics. This department, under Dr. A. S. McFarlane, has expanded more than any other of those from Hampstead, and now houses, in close proximity to each other, facilities for the application of many physical techniques to biological problems. Here are not only microscopy of various kinds, but also the routine photographical department, two electron microseopes, electrophoresis apparatus, ultrasonic equipment, electronic counters for radioactive isotopes, mass spectrometer for stable isotopes and some special freeze-drying and centrifuging equipment. The working benches are around the periphery of the wing; rooms for electron microscopes, photography, etc., are in the centre. At least half the time of those in the Division is taken up with work in collaboration with those in other departments. It is worth mentioning.in this connexion that it is the policy of the Director, as it was of his predecessor, Sir Henry Dale, to prevent the various divisions from becoming water-tight compartments. In fact, a very large number of the researches in progress are joint ventures involving one or more divisions of the Institute.

Also in the north-west wing is a well-equipped fine-instrument shop with an attached electronics laboratory and a drawing office.

In the north-east wing of the ground floor and in part of the first floor is housed the Division of Biochemistry, under the Director and Dr. A. Neuberger. Its interests are in the biochemistry of the 


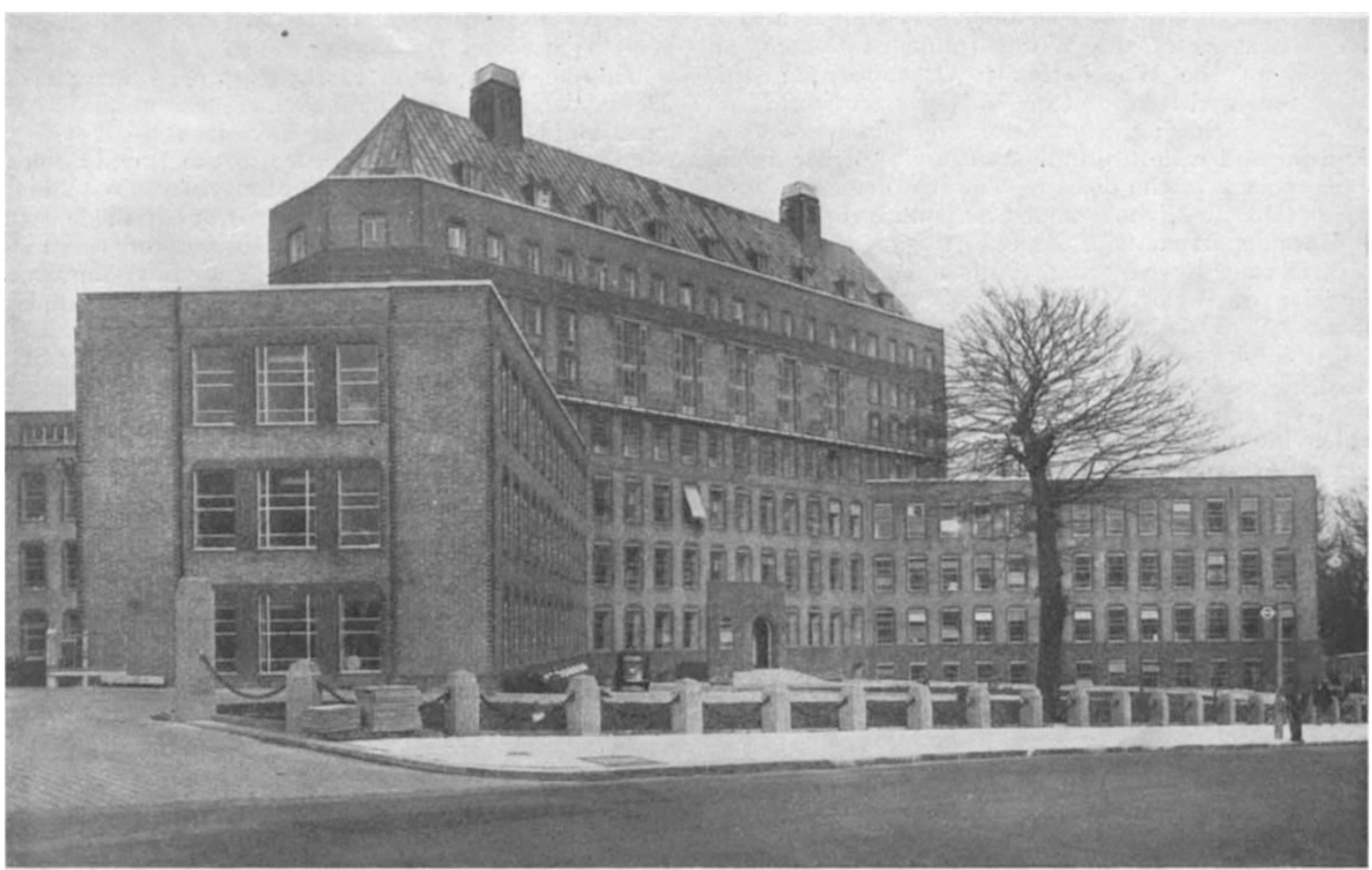

National Institute for Medical Research

Central Press Photos, Ltd.

thyroid, and in porphyrin and amino-acid metabolism. The application of radioactive isotopes to medical science is visible here in Dr. G. J. Popjak's studies of fatty-acid metabolism. Dr. A. J. P. Martin has lately joined the Institute's staff to pursue in the biochemistry department the art and science of paper chromatography. A radiochemical laboratory is in process of construction; it is intended to be used for the synthesis of compounds incorporating radioactive isotopes.

The north-west wing is largely devoted to the subject of chemotherapy, the development of which was largely responsible for the Institute's move. On the ground floor the laboratories of the Division of Organic Chemistry are mainly devoted to the chemical side of chemotherapy. Dr. Harold King, so long head of this Division, has just retired, being succeeded by Dr. J. Walker. Chemists working here have the advantage - which is, of course, mutual-of close contact with biologists in the field of chemotherapy (Drs. F. Hawking, J. D. Fulton and A. T. Fuller) working on the floor above them. New amœbicides and substances of potential activity against tuberculosis are among those now being synthesized and tested at the Institute. Other activities in the chemical laboratories concern cortisone, especially the testing of plant materials for possible precursors of cortisone; and co-operation with the department of pharmacology in the field of curarizing agents.

An important development in the Biological Chemotherapy Laboratories is the use of the lately discovered Plasmodium berghei for testing possible anti-malarials; this organism will infect mice, which are naturally more convenient than the canaries and ducklings which have been used so much in recent years. Chemotherapeutic research here is, however, tending to swing a little away from malaria and trypanosomiasis to the study of schistomiasis, filariasis and other worm infections. Leishmania and Entamoba histolytica also get their share of attention and, very naturally, the bacteria also, and, with luck, even the viruses. An appendage to this department is an insectarium for the rearing particularly of mosquitoes.

Also in the north-east wing is the Division of Bacterial Chemistry under Dr. M. R. Pollock. This Division contains the team formerly under the direction of Sir Paul Fildes at the Lister Institute. It is naturally hoped that their investigations on bacterial metabolism will contribute to the rational approach to chemotherapy.

Dr. W. J. Elford's small Division of Physical Chemistry is closely linked with biophysics on one hand, and with virus research on the other. Work is going on in all three of these Divisions to follow up the implications of the recent finding that recently isolated influenza viruses have filamentous forms.

In the centre block of the first floor is housed the Division of Experimental Biology under Dr. A. S. Parkes ; its name denotes the wider scope of activity of the former Department of Endocrinology. Its studies now are especially of the fertilization and cultivation of mammalian ova in vitro and of the behaviour and preservation of mammalian and avian sperm in vitro. Dr. Parkes is responsible for the husbandry of the animals bred for experimental purposes and, with Miss Bruce, has developed diets of cubed foods suitable for various species.

On the second floor, the centre block contains the Division of Virus Research, an activity associated with the Institute throughout its history. This is now under the charge of Dr. C. H. Andrewes, and is, at present, interested especially in virus infections of the respiratory tract. Based upon it is the Common 
Cold Research Unit at Salisbury. Within it also is the laboratory of the World Influenza Centre, an activity of the World Health Organisation; this keeps touch with laboratories all over the world and seeks, by gathering information and strains of virus from far and wide, to understand more of the global epidemiology of the disease. The histological laboratories (Dr. J. Niven) render help and co-operation to other departments of the Institute.

In the north-west wing of the second floor is the Division of Biological Standards, under Dr. A. A. Miles. The Institute undertakes responsibility for maintaining and distributing, under the World Health Organisation, standards cf all those substances such as sera, vitamins and hormones for which biological assay is necessary. Other work is concerned with the operation of the Therapeutic Substances Act. At present, forty-five international or British standards are held in the Institute. Help in relation to biological standards is rendered by many in various departments of the Institute, and the members of Dr. Miles's own laboratories are able to give a large proportion of their time to research. At the moment this concerns particularly the action of cortisone and other hormones, and of shock and physiological changes, on the processes of immunity and infection.

On the second floor, in close proximity to the virus and standards departments, are the media prepara. tion rooms. Here, and also among the viruses and standards, are special sterile rooms into which clean air is admitted under pressure after passing through filters situated above a false ceiling.

The 'Animal House' occupies the first and second floors of the south-west and north-west wings, and also the third floor of the latter. 'Two sets of swing doors cut it off from the rest of the building; but in any event the special ventilation system keeps it satisfactorily free from noxious smells. Some parts are thèrmostatically controlled. There are three separate isolation units-one specially for tuberculosis-and special precautions are applied to keep under control dangerous infections. Air from these units is treated separately from that from the rest of the building, being 'scrubbed' with chlorine before passing out by the incinerator chimney. The building contrins infected animals only; normal breeding stock is housed in separate buildings and cared for by separate staff.

As already mentioned, the Institute above the second floor consists of a central block only. The third floor has purposely not been completed, being held in reserve for future unforeseen developments. Some encroachment has, however, already had to be made on this reserve space, and laboratories are being fitted for special biochemical work.

The fourth and mezzanine floors contain the library, and there is a consensus of opinion that this is one of the best features of the Institute. The central room is spacious and airy ; there are extensive views to north and south from the windows; the most widely used journals are all easily accessible, the less-used ones being in the gallery above. There are side rooms for reference books and text-books, and ample stock rooms; also a series of small study rooms.

On the fifth floor is the canteen, which can seat 240 ; here the entire Institute staff can have lunch and tea, the mess being run on the cafeteria principle. There are coffee rooms for various sections of the staff.
In the sixth (attic) floor, besides storage tanks, are recreation rooms for assistant staff.

This account of the Institute is necessarily brief. Deliberately, little reference has been made to its past achievements, for these have been dealt with in Sir Charles Harington's lecture to the Royal Society little more than a year ago. Many of these achievements are well known ; if they are not equalled or surpassed in the new environment, the workers there will have only themselves to blame. They have, however, one major disadvantage to contend with : Mill Hill is five miles farther from almost everywhere than is Hampstead. It will be necessary to make no little effort to see that the flowers of research blooming at Mill Hill are well and truly cross-fertilized by those put forth elsewhere.

C. H. ANDREWES

\section{THE TWO TYPES OF WHEAT ENDOSPERM}

By E. N. GREER and DR. J. J. C. HINTON

Research Association of British Flour Millers, Cereals Research Station, St. Albans

FLOUR millers have long recognized two types of behaviour in the crushing of wheat endosperm, and distinguish between 'hard' and 'soft' types of wheat grain. The differences are such that the detailed layout of a modern mill is materially affected if required to grind either type separately. In a general sense, the hard wheat is easier to mill since it gives readier separation of bran from endosperm and the liberated flour is more mobile and easy to sift. Wheat grown in Britain, particularly the newer high-yielding varieties, is largely soft in character. An increase in the 'hardness' of the crop would therefore constitute an important improvement in the quality of the grain from the milling point of view.

Biffen", in his study "The Inheritance of Strength in Wheat", describes experiments in which grains were crushed on an iron plate. With some grains a fine powder was obtained, whereas others gave a gritty powder of angular fragments. In applying this test to the $F_{2}$ hybrids of a cross between soft and hard wheats (Rough Chaff and Red Fife) he noted that, judged in this way, the numbers of hard and soft hybrids produced were approximately in a Mendelian ratio. More recently, Berg ${ }^{2}$ has pointed out that the milling behaviour of wheat may be judged from the extent to which finely divided flour, passing through a No. 15 silk $(0.085 \mathrm{~mm}$. aperture), is produced in a standard milling process, and he has put forward further evidence suggesting that genetic factors govern milling behaviour. The application of Berg's technique to standard varieties of English wheat has confirmed the fact that milling behaviour is affected little by variations in the composition of the grain ${ }^{3}$.

The microscopic studies of flour from hard and soft wheat by Berliner and Rüter ${ }^{4}$ showed that the former contained a large proportion of intact endosperm cells. By contrast, the larger particles in the flour from soft wheat consisted of groups of torn endosperm cells, few or no whole cells being present.

Some observations made on wheat grains as distinct from flour are described below :

(1) Slices (about $0.5 \mathrm{~mm}$. thick) of completely vitreous grains were prepared by grinding the grains down on fine glasspaper. When viewed with a low- 